\title{
26297 - THE IMPACT OF A FORMAL MENTORSHIP PROGRAM IN AN ANESTHESIOLOGY ACADEMIC DEPARTMENT
}

\author{
Jerome O'Hara MD, Bierer Beth, MEd; Mariana Hewson, PhD; Stevens Sara, \\ Armin Schubert, MD, MBA \\ The Cleveland Clinic Foundation, Cleveland, OHIO, USA
}

INTRODUCTION: A mentor is a person who has acquired experience and seniority; who is more than a teacher or colleague; who serves as a sponsor, advisor and role-model; who has the time to counsel and support more junior people; a person whose high standards of excellence a protégé can emulate. ${ }^{2}$ In a previous survey of anesthesiologists, $71 \%$ (32/45) rated mentoring as important/very important. ${ }^{3}$ This study was designed to assess the impact for these anesthesiologists of mentorship after participating in a two-hour interactive faculty development mentorship workshop.

METHODS: Fifty-two anesthesiologists in an academic, tertiary care facility with a large residency program (>100 residents) were anonymously asked to complete a 17 -item questionnaire 2 weeks before, and three 3 months after attending a formal mentorship workshop. The purpose of the workshop was to further educate anesthesiologists on the following topics: departmental and institutional commitment for mentorship, examples of successful departmental mentorship relationships, and pathways for anesthesiologists to identify mentors. Anesthesiologists' ratings on pre vs. post-workshop questionnaires were compared using paired $t$ tests for individual responses and overall ratings (i.e., sum of all items). Results are presented as means (95\% confidence intervals).

RESULTS: Thirty-two anesthesiologists completed both questionnaires (66\% response rate). The majority were male (87\%), in the department for less than five years (31\%), and an average age of $47( \pm 9.1)$ years. Anesthesiologists' opinions about mentoring did not change significantly as a result of the workshop. Confidence intervals did reveal that anesthesiologists rated mentoring behaviors differently on the pre vs. post-workshop questionnaire. Post-workshop analysis rated the importance of mentoring in anesthesia significantly higher than posttest scores on mentoring in career so far, clinical medicine, and defining a balance between career and home (Fig).

CONCLUSIONS: Although anesthesiologists' ranked the importance of some mentorship attributes differently after participating in a mentorship workshop, their perceptions of mentoring did not change significantly when pre vs. post-workshop attitudes (obtained 3 months later) were compared. Thus, a single interactive mentorship workshop did not appear effective to establish a long term change in perceived benefits of mentoring. It is possible the issue is the actual need for implementation of a mentorship 
program. Therefore, we organized a targeted, comprehensive program which included a weekly research discussion hour, opportunities to attend professional development courses, and pathways to advance in professional societies. Individual anesthesiologist mentorship discussions with periodic surveys are planned to evaluate the effectiveness of this continued mentorship effort.

\section{REFERENCES:}

1. J Lab Clin Med 1997;129:487-91.

2. J Thorac Cardiovasc Surg 2000;119:S45-S48.

3. Anesth. Analg 98(2S);S-67, 2004

Post-Wotkshop Analysis

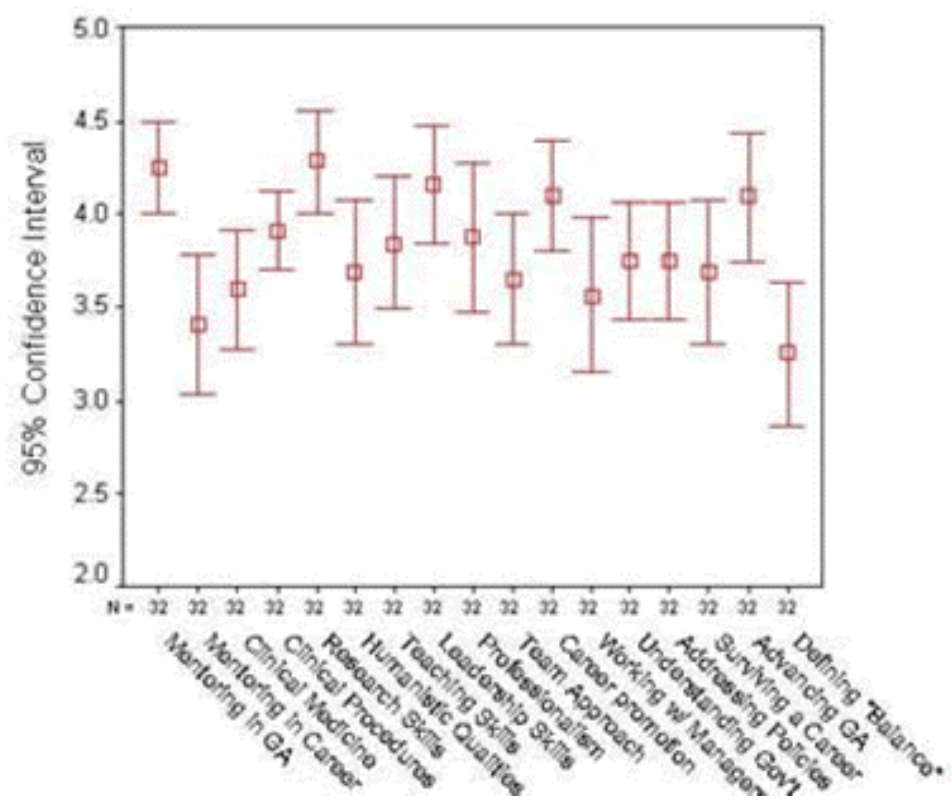

